A list of Working Papers on the last pages

No. 94

JOB MOBILITY AND WAGE GROWIH:

A STUDY OF SELECTION RULES AMD RFMARDS

by

Bertil Holmlund

This is a preliminary paper. It is intended for private circulation, and should not be quoted or referred to in publications without permission of the authors. Comments are welcome. 
CONTENTS

THE MODEI

Variables and Data

Empirical Results

Structural decision equations

Responses to tax changes

ConchusIows

FOOTNOTES

APPENDIX.

ON WAGE LEVEI AND WAGE CHANGE EQUATIONS

REFEREXCES 


\section{INTRODUCTION *}

The causes and consequences of labor mobility belong to the classical topics in labor economics. There is, first, the issue of the extent to which workers respond to pexceived wage gains associated with job mobility. The adaptability of the labor market in this respect has obvious implications for the speed at which potential allocation gains can be realized. It is also clear that mobility between jobs is a device through which workers can improve their economic position; individual wage and income mobility is presumably to a large extent associated with job mobility. Hence, an understanding of life-cycle patterns of earnings may require knowledge of mobility over the life cycle as well.

This paper has two interrelated objectives. The first one is to explore the role of expected wage gains for mobility decisions. The second aim is to investigate the effects of mobility on subsequent earnings. Do workers actually gain by moving or had they done better by not moving? This information, in turn, will illuminate the relationships between life cycle earnings profiles and life cycle patterns of job mobility.

The approach in this paper extends beyond a standard "naive" approach in mobility studies, where earnings differentials between stayers and movers are captured by a dumy variable in an earnings function. A tacit assumption in this traditional approach is that the computed wage differential (if positive) measures the stayers gain from moving, had they moved. However, the movers and stayers are not randomly selected groups but 
rather self-selected, presumably on the basis of perceived benefits associated with the alternatives. The earnings of movers are, therefore, not necessarily attributable to stayers, had they moved; nor are the stayers' earnings necessarily attributable to those who actually moved, had they not moved.

our analysis takes the interdependence between wage growth and mobility into account; wage growth rates are affected by mobility and the mobility decision responds to alternative prospective wage growth rates. The framework we use results in a model with binary and limited dependent variables. 1

\section{THE MODEL.}

Assume that the worker's mobility decision is based on a comparison between two prospective earnings streams, associated with job mobility and job staying, respectively. The worker knows, at each point in time, his actual wage and has anticipations about his wage growth. Mobility occurs if discounted life time earnings, net of job transfer costs, are improved, i.e..

$V_{\operatorname{mi}}-V_{s i}-C_{i}>0$

where $V_{m i}, V_{s i}$ are life time earnings (for the ith individual) related to moving and staying, respectively. The cost of changing job is denoted $\mathrm{C}_{i}$.

To simplify the analysis, we assume that the worker behaves as if his working life were of infinite length. Each worker is, however, facing a 
known and constant death risk, $\delta$. Likewise, he is aware of the possibility of involuntary separations from the firm. Denote the separation probability by $\mu$ and assume that the worker treats $\mu$ as a constant. There is, however, little reason to expect separation probabilities to be independent of the worker's mobility decision; because of seniority rules, we would expect higher layoff-risks in a hypothetical new firm than in the current one. Taking account of positive death and layoff risks, the "total" discount rate is

$\rho_{\mathrm{mi}}=r_{i}+\delta_{i}+\mu_{\mathrm{mi}}$

$\rho_{\text {si }}=r_{i}+\delta_{i}+\mu_{\text {si }}$

when $r_{i}$ is the conventional discount rate. The present values of earnings for the alternative options are then

$v_{m i}=\int_{0}^{\infty} w_{o i} \exp \left(g_{m i} t-p_{m i} t\right) d t=w_{o i} /\left(\rho_{m i}-g_{m i}\right)$

$v_{s i}=\int_{0}^{\infty} w_{o i} \exp \left(g_{s i} t-\rho_{s i} t\right) d t=w_{o i} /\left(\rho_{s i}-g_{s i}\right)$

where $w_{0}$ is the initial wage rate and $g_{m}$, $g_{s}$ are rates of wage growth associated with mobility and staying, respectively.

The wage growth functions related to mobility and staying are given by

$g_{\mathrm{mi}}=\mathrm{x}_{\mathrm{i}} \beta_{\mathrm{m}}+\varepsilon_{\mathrm{mi}}$ 
$g_{s i}=x_{i} \beta_{s}+\varepsilon_{s i}$

where $\varepsilon_{\mathrm{m}} \sim N\left(0, \sigma_{1}\right), \varepsilon_{\mathrm{s}} \sim N\left(0, \sigma_{2}\right)$

and, likewise, the discount rates are given by

$\rho_{\mathrm{mi}}=Q_{\mathrm{mi}} \gamma_{\mathrm{m}}+\eta_{\mathrm{mi}}$

$\rho_{s i}=\Omega_{s i} \gamma_{s}+\eta_{s i}$

where $\eta_{\mathrm{m}} \sim \mathrm{N}\left(0, \sigma_{3}\right), \eta_{\mathrm{s}} \sim\left(0, \sigma_{4}\right)$

Assume, next, that job transfer costs are proportional to prospective income with the current employer, and related to a vector $z$ of various personal and other characteristics, i.e.2,

$c_{i} / v_{s i}=z_{i} \ominus+u_{i}$

where $u_{i} \sim \mathbb{N}\left(0, \sigma_{5}\right)$

Let $I_{i}$ denote the selection index and let $c_{i}=c_{i} / v_{s i}$. The criterion for moving becomes then

$I_{i}=\ln \left(v_{\mathrm{mi}} / \mathrm{V}_{\mathrm{si}}\left(1+\mathrm{C}_{i}\right)\right)=$

$=-\ln \left(\rho_{m i}-g_{m i}\right)+\ln \left(\rho_{s i}-g_{s i}\right)-\ln \left(1+c_{i}\right)>0$

which, through a Taylor approximation around the means, is rewritten as

$I_{i}=\alpha_{0}+\alpha_{1}\left(g_{m i}-p_{m i}\right)+\alpha_{2}\left(g_{s i}-p_{s i}\right)+\alpha_{3} c_{i}$

where $\alpha_{1}=1 /\left(\bar{\rho}_{\mathrm{m}}-\bar{g}_{\mathrm{m}}\right), \alpha_{2}=-1 /\left(\bar{\rho}_{\mathrm{s}}-\overline{\mathrm{g}}_{\mathrm{s}}\right)$ and $\alpha_{3} \approx 1$ (assuming $c_{i}$ to be small). 
The wage growth equations (6) and (7) cannot be estimated for all individuals; $g_{\mathrm{m}}$ is only observed for those who move, $g_{s}$ only for those who stay. The conditional expectations are

$E\left(g_{m i} \mid I_{i}>0\right)=x_{i} \beta_{m}+E\left(\varepsilon_{m i} \mid I_{i}>0\right)$

$E\left(g_{s i} \mid I_{i} \leqslant 0\right)=x_{i} \beta_{s}+E\left(\varepsilon_{s i} \mid I_{i} \leqslant 0\right)$

Those observed mean wage increases may differ from the population means if the exror terms pertaining to the censored samples have non-zero means. The approach followed involves finding explicit expressions for the error terms. Substitute, therefore, Eqs. (6) - (10) into Eq. (12)

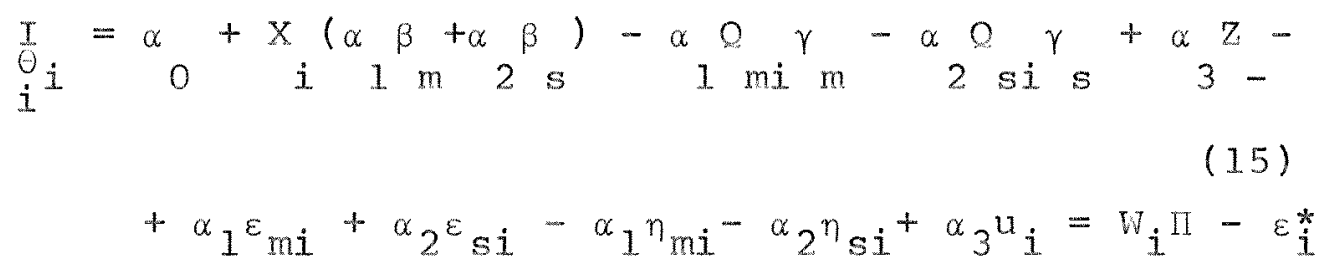

where

$W_{i}=\left(x_{i}, O_{m i}, Q_{s i}, z_{i}\right)$ and

$-\varepsilon_{i}^{*}=\alpha_{1} \varepsilon_{\mathrm{mi}}+\alpha_{2} \varepsilon_{\mathrm{si}}-\alpha_{1} \eta_{\mathrm{mi}}-\alpha_{2} \eta_{\mathrm{si}}+\alpha_{3} u_{i} \cdot$

The probability of observing a person as mover is accordingly

$\operatorname{Pr}\left(I_{i}>0\right)=\operatorname{Pr}\left(W_{i} \Pi>\varepsilon^{*}\right)=F\left(W_{i} \Pi / \sigma_{\varepsilon} *\right)$

where $F(\cdot)$ is the standardized cumulative normal density function. Obviously,

$\operatorname{Pr}\left(I_{i} \leqslant 0\right)=1-F(\cdot)$ 
Next, define $\lambda_{\mathrm{mi}}$ and $\lambda_{\mathrm{si}}$ as

$\lambda_{\operatorname{mi}}=-\mathbf{E}\left(\mathrm{W}_{i} \Pi / \sigma_{\varepsilon} *\right) / \mathrm{F}(\cdot)$

$\lambda_{s i}=f\left(W_{i} \Pi / \sigma_{\varepsilon}\right) /(1-F(\cdot))$

It can be shown that

$E\left(\varepsilon_{\operatorname{mi}} \mid \varepsilon_{i}^{*}<W_{i} \Pi\right)=\left(\sigma_{1 \varepsilon} / \sigma_{\varepsilon}\right) \lambda_{\operatorname{mi}}$

$E\left(\varepsilon_{s i} \mid \varepsilon_{i}^{*} \geqslant W_{i} I I\right)=\left(\sigma_{2 \varepsilon^{*}} / \sigma_{\varepsilon^{*}}\right) \lambda_{\mathrm{si}}$

where $\sigma_{1 \varepsilon}$ and $\sigma_{2 \varepsilon}$ are covariance terms. Hence

it turns out that non-zero covariances may introduce sample selection bias. If the error in the decision equation is uncorrelated with the errors in the wage equations, no bias will occur. Note, however, that oLs-estimation and non-zero covariances will only bias the intercept if the relevant selection variable is uncorrelated with the variables included in the $\mathrm{X}$-vector.

The estimating wage change equations, conditional. on observed mobility status, will be

$$
\begin{aligned}
& g_{m i}=x_{i} \beta_{m}+k_{m} \hat{\lambda}_{m i}+\xi_{m i} \\
& g_{s i}=x_{i} \beta_{s}+k_{s} \hat{\lambda}_{s i}+\xi_{s i}
\end{aligned}
$$

where $E\left(\xi_{m i} \mid I_{i}>0\right)=0, E\left(\xi_{s i} \mid I_{i} \leqslant 0\right)=0$, $\kappa_{m}=\sigma_{1 \varepsilon} / \sigma_{\varepsilon} *$ and $\kappa_{s}=\sigma_{2 \varepsilon} * \sigma_{\varepsilon} *$ 
The introduction of the variables $\hat{\lambda}_{\mathrm{mi}}$ and $\hat{\lambda}_{\mathrm{si}}$, predicted from the reduced form probit (16), will result in consistent oLs-estimates purged of selection bias (at least if no other sources of selectivity bias exist).

The estimated wage change equations yield predicted wage growth rates for each individual, $\hat{g}_{m i}$ and $\hat{g}_{\mathrm{si}}$, which can be substituted back into the structural index,

$I_{i}=\alpha_{0}+\hat{\alpha}_{1} g_{m i}+\hat{\alpha}_{2} g_{s i}-\alpha_{1} \rho_{m i} \gamma_{m}-\alpha_{2} \rho_{s i} \gamma_{s}+\alpha_{3} z_{i} \theta-\varepsilon_{i}^{*}$

which, again, is estimable by probit. It can be noted that the parameter vectors $\gamma_{m}, \gamma_{s}$ and $\theta$ show up in the same form in the reduced form index as in the structural index.

\section{Variables and data}

The data analyzed are from the Swedish Level of Living surveys of 1968 and 1974. In particular, we will explore the determinants of mobility and wage growth for male workers between 1968 and 1974 . Mobility is defined as change of employer and is implicitly given by the respondents' reports on tenure in the 1974 survey. Workers who report 1968 as hiring year both in 1968 and in 1974 were excluded from the sample (since change of employer is uncertain in this case). Workers with uncertain wage reports were also excluded, as were persons with unemployment experiences during the period. The reason for the latter restriction is that our framework may not apply to job changes due to 
"involuntary" unemployment. There is no possibility of distinguishing different types of unemployment in the current data set.

The general framework outlined includes five stochastic equations. The two wage growth equations include a vector of explanatory variables specified as follows:

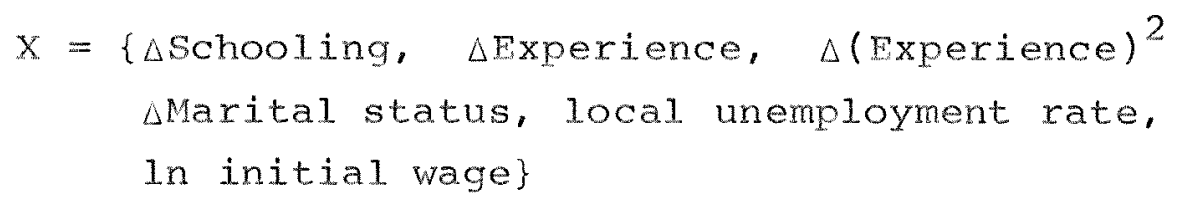

This corresponds to a standard human capital earnings function, where log earnings are explained by education, work experience and work experience squared (and possibly some other personal characteristics as well). ${ }^{3}$ Changes in 109 earnings will accordingly be related to changes in the human capital attributes. We have also added the local unemployment rate to the wage change equation, capturing responses to varying degrees of labor market tightness.

The period of investigation is characterized by ambitious efforts by the trade unions to reduce existing wage differentials (the so called wage policy of solidarity). Simultaneously, a marked increase in university educated manpower has occured. Those changes may have affected the returns to schooling and on-the-job training. We take account of this possibility by including the initial wage level in the wage change equation. It can be shown that this specification amounts to a uniform proportional change of all parameters of the wage level equations. See Appendix for details. 
The vector $z$, capturing mobility costs, is given as

$z=\left\{\right.$ tenure, $\left(\right.$ tenure) ${ }^{2}$, age, marital status, recently moved

The arguments are basically self-explanatory. The worker's ties with the employer will increase with, first of all, his length of tenure. This is due to accumulated firm-specific human capital, but also to firm-specific ties arising from established social relations with co-workers. It is also to be expected that mobility costs are higher for older workers, for married ones and for persons with a substantial length of residence in the current locality.

The Q-vectors explaining discount rates are specified to include tenure and age variables. In particular, workers with short tenure are facing higher layoff risks with their current employer. And old workers are likely to place more emphasis on returns in the near rather than in the distant future. Hence,

$\mathrm{o}_{\mathrm{m}}=\{$ age $\}$

$\mathrm{o}_{\mathrm{s}}=\left\{\right.$ tenure, $(\text { tenure) })^{2}$, age

A summarizing description of the data is given in Table 1. It can be observed that movers generally tend to be younger, less frequently married and with shorter length of tenure. The initial wage level is lower for movers, whereas their rate of wage growth is higher than the average. In terms of nominal growth rates per year, movers receive 11.9 percent and stayers 9.4 percent. In real terms (before taxes) these figures imply 5.3 percent for movers and 2.8 percent for stayers. 
Table 1 Sample characteristics

All workers Job movers Job stayers

Age

37

32

40

Recently moved to

current locality

$(=1$ if the person

moved in 1967 or 1968 ,

zero otherwise)

0.09

0.14

0.06

$\Delta$ Schooling

0.8

1.1

0.7

$\Delta$ Experience

$5 \cdot 2$

$4 \cdot 9$

$5 \cdot 3$

Marital status

$(=1$ if married, zero

otherwise)

0.73

0.55

0.81

$\Delta$ Marital status

0.10

0.22

0.05

Tenure

9.8

5.2

12.0

Local unemployment

rate

$2.1 \quad 2.1 \quad 2.1$

In initial wage

7.066

6.959

7.116

Real wage increase

per year, percent

$\begin{array}{lll}3.6 & 5.3 & 2.8\end{array}$

Sample size

1047

330

717

Note: The figures refer to 1968 and to changes between $\overline{1968}$ and 1974 . The wage rate is earnings per hour in Swedish orre. The local unemployment rate is the average for 1970-73 of unemployment rates in regions of co-operating municipalities ("A-regions"). Age, Schooling, Experience and Tenure are measured in years. 


\section{Empirical Results}

The first step of the estimation procedure involves estimating the reduced form probit, as given by Eq. (16). The results are set out in the first two columns of Table 2. As spelled out above, the reduced form includes arguments of the wage growth equations as well as the equations for mobility costs and discount rates.

The wage change equations include the initial wage level among the RHS variables. There is, however, reason to question the assumption of uncorrelatedness of the initial wage level with the error terms of the wage change equations (see Appendix). We applied the Wu test as a check. ${ }^{4}$ The (log) initial wage level was regressed on a number of personal characteristics and human capital attributes and the residuals were appended as a new variable to the wage change equation. The coefficients on the residual variables were significantly different from zero in both wage change equations, thus indicating possible simultaneous equations bias.

The estimates presented are, therefore, given under two alternative assumptions about the error terms of the wage change equations. First, we maintained the hypothesis of uncorrelatedness between errors and RHS variables; hence the initial wage was used as regressor. Secondly, the initial. wage was treated as endogenous and therefore predicted by a set of instrumental variables.

The reduced form estimates are used to compute selectivity variables, $\hat{\lambda}_{\mathrm{mi}}$ and $\hat{\lambda}_{\mathrm{si}}$, respectively. Those are appended to the estimating wage change equations. The results are given in Table 3 . 
Table 2 Estimated decision equations

\begin{tabular}{|c|c|c|c|c|c|}
\hline & Reduced & form & & ructural fo & orm \\
\hline & (1) & (2) & (3) & $(4)$ & (5) \\
\hline Constant & $\begin{array}{l}2.129 \\
(2.415)\end{array}$ & $\begin{array}{c}0.872 \\
(0.691)\end{array}$ & $\begin{array}{c}0.474 \\
(3.086)\end{array}$ & $\begin{array}{c}0.090 \\
(0.423)\end{array}$ & $\begin{array}{c}0.057 \\
(0.153)\end{array}$ \\
\hline$\hat{g}_{\mathfrak{m}}$ & & & $\begin{array}{l}17.02 \\
(2.552)\end{array}$ & $\begin{array}{l}14 \cdot 30 \\
(2 \cdot 228)\end{array}$ & $\begin{array}{l}14.67 \\
(2.010)\end{array}$ \\
\hline$\hat{9}_{s}$ & & & $\begin{array}{l}-24.86 \\
(-2.222)\end{array}$ & $\begin{array}{l}-20.92 \\
(-1.861)\end{array}$ & $\begin{array}{l}-21.31 \\
(-1.803)\end{array}$ \\
\hline $\begin{array}{l}\text { Recently moved to } \\
\text { current locality }\end{array}$ & $\begin{array}{c}0.294 \\
(1.949)\end{array}$ & $\begin{array}{c}0.274 \\
(1.807)\end{array}$ & $\begin{array}{c}0.269 \\
(1.809)\end{array}$ & $\begin{array}{c}0.254 \\
(1.712)\end{array}$ & $\begin{array}{c}0.256 \\
(1.710)\end{array}$ \\
\hline Tenure & $\begin{array}{l}-0.113 \\
(-7.802)\end{array}$ & $\begin{array}{l}-0.115 \\
(-8.011)\end{array}$ & $\begin{array}{l}-0.108 \\
(-7.583)\end{array}$ & $\begin{array}{l}-0.110 \\
(-7.587)\end{array}$ & $\begin{array}{l}-0.111 \\
(-7.569)\end{array}$ \\
\hline$(\text { Tenure })^{2} / 100$ & $\begin{array}{c}0.214 \\
(5.397)\end{array}$ & $\begin{array}{l}0.225 \\
(5.827)\end{array}$ & $\left(\begin{array}{l}0.211 \\
(5.278)\end{array}\right.$ & $\begin{array}{c}0.215 \\
(5.364)\end{array}$ & $\begin{array}{c}0.215 \\
(5.350)\end{array}$ \\
\hline Married & $\begin{array}{l}-0.319 \\
(-2.485)\end{array}$ & $\begin{array}{l}-0.377 \\
(-2.847)\end{array}$ & $\begin{array}{l}-0.347 \\
(-3.304)\end{array}$ & $\begin{array}{l}-0.431 \\
(-3.848)\end{array}$ & $\begin{array}{l}-0.433 \\
(-3.822)\end{array}$ \\
\hline $\begin{array}{l}\text { Local unemploy- } \\
\text { ment rate }\end{array}$ & $\begin{array}{l}0.006 \\
(0.116)\end{array}$ & $\begin{array}{c}0.010 \\
(0.210)\end{array}$ & & & \\
\hline In initial wage & $\begin{array}{l}-0.207 \\
(-1.620)\end{array}$ & & & & \\
\hline $\begin{array}{l}\text { In predicted } \\
\text { initial wage }\end{array}$ & & $\begin{array}{c}0.119 \\
(0.583)\end{array}$ & & & \\
\hline Age & & $\begin{array}{l}-0.027 \\
(-2.166)\end{array}$ & & & $\begin{array}{r}0.0006 \\
(0.108)\end{array}$ \\
\hline$\Delta$ Marital status & $\begin{array}{c}0.143 \\
(1.100)\end{array}$ & $\begin{array}{c}0.113 \\
(0.862)\end{array}$ & & & \\
\hline$\Delta$ Schooling & $\begin{array}{c}0.045 \\
(1.454)\end{array}$ & $\begin{array}{c}0.037 \\
(1.214)\end{array}$ & & & \\
\hline$\Delta$ Experience & $\begin{array}{l}-0.077 \\
(-2.179)\end{array}$ & $\begin{array}{l}-0.173 \\
(-3.113)\end{array}$ & & & \\
\hline $\begin{array}{l}\Delta(\text { Experience })^{2} / \\
1 \text { 000 }\end{array}$ & $\begin{array}{l}-0.019 \\
(-0.046)\end{array}$ & $\begin{array}{c}0.002 \\
(1.989)\end{array}$ & & & \\
\hline Log likelihood & -543.22 & -542.00 & -545.55 & -547.66 & -547.65 \\
\hline Likelihood ratio & 218.51 & 220.96 & 213.86 & 209.64 & 209.65 \\
\hline
\end{tabular}


Table 3 Estimated wage growth equations

Dependent variable: In(1974 Wage) - In(1968 Wage)

\begin{tabular}{|c|c|c|c|c|}
\hline & $\begin{array}{l}\text { Job st } \\
\text { (1) }\end{array}$ & $\begin{array}{r}\text { ayers } \\
(2)\end{array}$ & $\begin{array}{l}\text { Job mo } \\
(3)\end{array}$ & vers \\
\hline Constant & $\begin{array}{r}3.146 \\
(20.73)\end{array}$ & $\begin{array}{r}2.295 \\
(10.22)\end{array}$ & $\begin{array}{r}4.872 \\
(19.70)\end{array}$ & $\begin{array}{l}3.440 \\
(7.177)\end{array}$ \\
\hline$\triangle$ Schooling & $\begin{array}{c}0.012 \\
(2.280)\end{array}$ & $\begin{array}{c}0.006 \\
(0.904)\end{array}$ & $\begin{array}{c}0.022 \\
(2.531)\end{array}$ & $\begin{array}{c}0.023 \\
(1.963)\end{array}$ \\
\hline$\Delta$ Experience & $\begin{array}{c}0.014 \\
(2.392)\end{array}$ & $\begin{array}{l}0.005 \\
(0.791)\end{array}$ & $\begin{array}{c}0.011 \\
(1.208)\end{array}$ & $\begin{array}{c}0.006 \\
(0.437)\end{array}$ \\
\hline $\begin{array}{l}\Delta(\text { Experience })^{2} / \\
1000\end{array}$ & $\begin{array}{l}-0.236 \\
(-3.774)\end{array}$ & $\begin{array}{l}-0.191 \\
(-2.627)\end{array}$ & $\begin{array}{l}-0.551 \\
(-4.363)\end{array}$ & $\begin{array}{l}-0.483 \\
(-2.897)\end{array}$ \\
\hline DMarital status & $\begin{array}{c}0.008 \\
(0.382)\end{array}$ & $\begin{array}{c}0.015 \\
(0.598)\end{array}$ & $\begin{array}{c}0.014 \\
(0.462)\end{array}$ & $\begin{array}{l}-0.003 \\
(-0.078)\end{array}$ \\
\hline $\begin{array}{l}\text { Local unemploy- } \\
\text { ment rate }\end{array}$ & $\begin{array}{l}-0.013 \\
(-1.720)\end{array}$ & $\begin{array}{l}-0.015 \\
(-1.657)\end{array}$ & $\begin{array}{l}-0.013 \\
(-0.890)\end{array}$ & $\begin{array}{l}-0.019 \\
(-0.992)\end{array}$ \\
\hline In initial wage & $\begin{array}{r}-0.368 \\
(-18.28)\end{array}$ & - & $\begin{array}{r}-0.599 \\
(-16.46)\end{array}$ & - \\
\hline $\begin{array}{l}\text { In predicted } \\
\text { initial wage }\end{array}$ & - & $\begin{array}{l}-0.246 \\
(-8.151)\end{array}$ & - & $\begin{array}{l}-0.375 \\
(-5.443)\end{array}$ \\
\hline$\hat{\lambda}_{\mathrm{s}}$ & $\begin{array}{c}0.057 \\
(1.669)\end{array}$ & $\begin{array}{c}0.108 \\
(2.735)\end{array}$ & - & - \\
\hline$\hat{\lambda}_{\mathrm{m}}$ & - & - & $\begin{array}{l}-0.012 \\
(-0.264)\end{array}$ & $\begin{array}{c}0.085 \\
(1.351)\end{array}$ \\
\hline $\mathrm{R}^{2}$ & 0.414 & 0.190 & 0.561 & 0.231 \\
\hline MSE & 0.033 & 0.045 & 0.058 & 0.101 \\
\hline$F$ & 71.66 & 23.74 & 58.82 & 13.84 \\
\hline
\end{tabular}

Note: Figures in parentheses are t-ratios. 
The human capital variables have signs consistent with a priori expectations. Wage rates increase with improved education and increase, at a decreasing rate, with years of work experience; the negative (and highly significant) sign for the coefficient of the squared experience variable implies lower wage growth rates for older workers. The local unemployment rate shows up with coefficients of expected signs, although with fairly large standard errors.

Another finding deals with the role of the initial wage rate. It appears as if initial earnings have substantial detrimental effects on wage growth during this period. This is consistent with various other evidence of a reduction in wage dispersion. It is beyond the scope of this paper to explore the causes beyond this process of wage equalization. Suffice it here, again, to mention that significant changes in the supply of university educated manpower have taken place. And the importance of the "wage policy of solidarity", pursued by the trade unions in centralized collective bargaining, could hardly be overlooked.

To what extent do the experiences of actual movers also capture what a random sample of workers would have earned, had they moved? The evidence on selection bias in the movers' wage equation is inconclusive. There is some weak indication of negative selection bias when the predicted initial wage is used as regressor. (Note that $\hat{\lambda}_{m}$ is negative; a positive coefficient implies therefore a negative selection effect.)

The evidence on selection bias is more conclusive when we turn to the stayers' wage equation. The 
estimated $\hat{\lambda}_{\mathrm{s}}$-coefficients are positive in both forms of wage change equations, implying positive censoring effects (since $\hat{\lambda}_{s}>0$ ). The implication is that those who chose to stay did bettex as stayers than what measurably similar movers would have done, had they decided not to move.

A selection rule based on comparative advantage would suggest that individuals choose mobility status on the basis of perceived benefits associated with the alternatives. Those actually observed as movers (stayers) would be precisely those who are likely to benefit from being movers (stayers). This leads us to expect positive, rather than negative, censoring effects.

The comparative advantage story may, however, disguise other selection rules of importance for wage growth. Suppose that a worker's inherent ability can be revealed by employers only after some initial period of employment. A firm's decisions on promotions and specific training will result in steeper wage paths for those revealed to be more productive; the employer will try to arrive at a wage distribution in conformity with the productive abilities of the workforce. This process will involve incentive schemes that discourage quits among the more productive workers. Those who are observed as stayers are likely to be more able and therefore more firmly attached to the firm. However, they might have been more able even in another firm (do better than the movers, had they decided not to stay). If job mobility to a large extent occurs because of "poor matching" between workers and firms, negative selection effects for movers should be of no surprise. 
In the previous sections we compared wage growth among measurably similar movers and stayers. We now ask different questions: Do movers gain by moving? or had they done better by not moving? Analogous questions are of course relevant for stayers.

The measurement of gains from mobility requires that movers are compared to movers (and stayers to stayers). The computations are straightforward. The mean characteristics of movers are appplied to the stayers wage function, hence giving a hypothetical wage change for movers, had they stayed. Analogously, the typical characteristics of the stayers are confronted with the movers wage equation, resulting in a calculated wage increase for stayers, had they moved. The results are shown in Table 4 .

It is obvious that movers do gain by moving; the yearly wage growth rate is increased by somewhat above 2 percentage points for job movers, compared to a situation where they had stayed. Movers appear to gain by moving, but do stayers also gain by staying? The answer is no; stayers forgo wage gains around 2 percentage points by refusing to move, presumably because of substantial mobility costs.

\section{Structural decision equations}

The worker's mobility decision is by assumption based on a comparison of two alternative earnings streams, associated with job mobility and job staying, respectively. The estimated wage growth equations allow us to impute those alternative wage paths to each indidivual. Hence, we obtain the 
Table 4 Actual and hypothetical real wage growth rates $1968-74$.

Percent per year

\begin{tabular}{clcl}
\hline & $\begin{array}{l}\text { Actual wage wage growth, wage growth, } \\
\text { growth } \\
\text { staying }\end{array}$ \\
\hline Al1 workers & 3.6 & 5.5 & 2.3 \\
Age 16-29 & 6.2 & 8.2 & 3.8 \\
Age 30-49 & 2.5 & 4.5 & 1.7 \\
Age 50- & 1.9 & 3.4 & 1.4 \\
Movers & 5.3 & $(6.7)$ & 3.0 \\
Stayers & 2.8 & 4.9 & $(2.0)$ \\
\hline
\end{tabular}

Note: Figures in parentheses show estimated mean wage increases for workers with observed characteristics identical to those of actual movers and actual stayers, respectively. The differences between those estimates and actual mean wage growth rates for the two groups are due to the censoring effects. The estimates in column (2) and column (4) of Table 3 have been used. 
estimable structural decision equation. The results are displayed in the last three columns of Table 2 .

of special interest here is to see whether workers respond to their potential wage gains. As is shown in the table, the coefficients for $\hat{g}_{m}$ and $\hat{g}_{s}$ have the expected signs and with (absolute) t-values around 2. An increase in $\hat{g} m$ by 1 percentage point implies an increase in the probability of moving by 0.05 (Table 5). Likewise, an increase in $\hat{\mathrm{g}}_{\mathrm{s}}$ by 1 percentage point will reduce the mobility probability by 0.07 . Job mobility decisions are clearly affected by prospective wage gains.

Among other results, we observe that length of tenure is a highly significant determinant of job mobility. More surprising is the insignificance of the age-coefficient in the structural probit. Age is (inversely) correlated with mobility gains (see Table 4), which partly may explain this anomalous result. Finally, we can note that married workers have much lower probabilities of moving than those who are not married.

It is noteworthy that the average discount rates, $\bar{\rho}_{m}$ and $\bar{\rho}_{s}$, are exactly identified in the model. The estimates taken together with Eq. (12) imply that

$\hat{\alpha}_{1}=1 /\left(\bar{\rho}_{\mathrm{m}}-\bar{g}_{\mathrm{m}}\right)=14.298$

$\hat{\alpha}_{2}=-1 /\left(\bar{\rho}_{\mathrm{S}}-\bar{g}_{\mathrm{S}}\right)=-20.919$

Estimates of $\bar{g}_{m}$ and $\bar{g}_{s}$ are given in Table 4. Using the values for the typical worker, we 
Table 5 Changes in job mobility probabilities due to changes in the determinants of job mobility
$\Delta F(\cdot)$
$\Delta F(\cdot) / F(\cdot)$

Increase in $\hat{g}$

by 1 percentage point $0.048 \quad 0.171$

Increase in $\hat{g}$

by 1 percentage point $\quad-0.071 \quad-0.249$

Increase in

tenure by 1 year

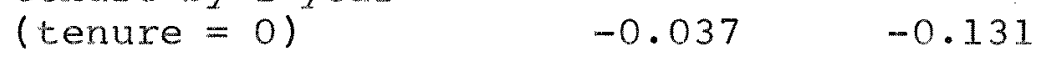

Increase in

tenure by 1 year

(tenure $=10$ )

$-0.023-0.081$

Change in marital

status

$-0.146 \quad-0.514$

Recently moved to

current locality

$0.086 \quad 0.303$

Note: The partial derivative of the probit model is calculated for values of the normal density, corresponding to the mean value of the probit index, i.e., $f(\cdot)=f(\bar{I})$, $F(\cdot)=F(\bar{I})$. The estimates in column (4) of Table 2 have been used. 
have $\bar{\rho}_{\mathrm{m}}=0.125$ and $\bar{\rho}_{\mathrm{s}}=0.071$. As noted above, there is little reason to expect the two discount rates to be equal. The finding that $\bar{p}_{m}$ is greater than $\bar{\rho}_{s}$ is consistent with the conjecture that the average worker expects higher layoff-risks in the hypothetical new firm than in the current one. This is a quite reasonable implication, since a change of employer involves loss of seniority rights.

\section{Responses to tax changes}

We have so far said nothing explicit about the role of progressive taxes for mobility decisions. Indeed, it is reasonable to expect that workers care about the net benefits associated with job mobility. Let us therefore illustrate the impact of tax changes by introducing a particular parameterization of the tax system. Let $W_{n}$ denote disposable income and assume that income after tax is an iso-elastic function of pre-tax income, i.e.,

$\ln W_{\mathrm{n}}=\mathrm{E} \ln W$

where $E=d \ln _{\mathrm{n}} / \mathrm{d} \ln W$ shows the percentage increase in net income resulting from an increase in gross income by one percent. It is easily shown that $E=(1-m) /(1-t)$, where $m$ is the marginal and the average tax rate. A lower value of $E$ corresponds to a more progressive tax system; the Lorenz curve will be shifted towards the origin with decreasing values of $\mathrm{E} .5$

Now, assume that workers focus on net earnings; hence, they will compare

$$
v_{m}^{*}=w_{o n} /\left(p_{m}-g_{m}^{*}\right)
$$


with

$\mathrm{V}_{\mathrm{s}}^{*}=\mathrm{W}_{\mathrm{on}} /\left(\rho_{\mathrm{s}}-\mathrm{g}_{\mathrm{m}}^{*}\right)$

where $g_{m}^{*}$ and $g_{s}^{*}$ are real wage growth rates after taxes, i.e., $g_{\mathrm{m}}^{*}=g_{\mathrm{m}} \mathrm{E}_{\mathrm{m}}$ and $g_{\mathrm{s}}^{*}=g_{\mathrm{s}} \mathrm{E}_{\mathrm{s}}$. If $\mathrm{E}_{\mathrm{m}}=\mathrm{E}_{\mathrm{s}}$ ' it is straigthforward to see that the structural decision equation will be

$I=\alpha_{0}^{*}+\alpha_{1}^{*}\left(E g_{m}-\rho_{m}\right)+\alpha_{2}^{*}\left(E g_{s}-\rho_{s}\right)+\alpha_{3}^{*} \mathrm{C}$

instead of $\mathrm{Eq}$. (12). The relationship between the estimates in (12) and (27) will be

$\hat{\alpha}_{1}=\hat{\alpha}_{1}^{*}$ and $\hat{\alpha}_{2}=\hat{\alpha}_{2}^{*} \mathrm{E}$.

We just have to divide our estimated coefficients from (12) by the tax elasticity to obtain estimates of responses to increases in real wage growth rates net of taxes. Likewise, we can easily compute mobility responses to changes in the progressivity of the tax system. We have

$\frac{\delta I}{\delta E}=\left(\hat{\alpha}_{1} / E\right) \bar{g}_{m}+\left(\hat{\alpha}_{2} / E\right) \bar{g}_{S}$

It is of some interest to note that (28) has no presumtive sign; it may be positive, as intuition would suggest, but a negative sign cannot be ruled out. The reason for this ambiguity lies in the fact that lower progressivity increases life time earnings related to both moving and staying.

Given our estimates of the relevant parameters $\left(\hat{\alpha}_{1}, \hat{\alpha}_{2}, \bar{g}_{m}, \bar{g}_{s}\right)$ we can conclude that the mobility 
response to a lower progressivity will be positive in sweden. We have

$\frac{\delta I}{\delta E}=0.306(1 / E)>0$

The magnitude of this effect is, however, rather sma11. A decrease in $F$, from, say, 0.75 to 0.65 , would decrease the mobility rate for this pexiod by somewhat more than one percentage point. Again, it should be emphasized that those exercises are based on a parameterization of the tax system that involves approximations of reality. In a more ambitious treatment of progresive taxes, one might want to make the tax elasticity endogenous. Such an approach, however, is beyond the scope of this paper. 


\section{CONCLUSIONS}

We have analysed the determinants and consequences of individual mobility behavior in the Swedish labor market. Since workers are likely to move in response to their potential wage gains, there is a two-way causality between mobility and wage growth. The econometric procedures utilized in this paper take this interdependence into account.

The results of the empirical analyses indicate that actual job movers obtain around 2 percentage points higher real wage growth compared to a situation where they had decided not to move. It is also interesting to see that potential mobility gains are decreasing over the life cycle, thus providing one piece of an economic interpretation of observed life cycle patterns of mobility and earnings. The traditional human capital explanation of life cycle earnings profiles appear to need an extension to account for mobility behavior over the life cycle (and wage gains associated with this mobility).

Population heterogeniety is likely to interfere with unbiased estimates of the returns to individual job changes. We find evidence of positive selfselection for stayers; a random group of workers will experience lower wage growth rates as stayers than what actual stayers obtained. The evidence on self-selection is less conclusive for movers, although the "preferred equation" provides some weak evidence of negative self-selection.

An interesting consequence of the adopted procedure is the possibility of estimating structural decision equations, where hypothetical wage growth 
rates enter as arguments. We find that workers respond to their "opportunity wages" in the expected direction.

A number of issues have been left out of focus in the present paper. For example, the treatment of taxes has been illustrative rather than thorough. The interrelationships between mobility and labor supply decisions have also been ignored; we have throughout the paper implicitly assumed hours worked to be fixed. In future research, it would be of interest to deal with those decisions in a unified theoretical and econometric framework. Finally, it would be desirable to view mobility decisions in a household perspective; the presence of various family ties are clearly of importance for inter-local job changes. 


\section{FOOTNOTES}

* A previous version of this paper was presented at labor workshops at the University of Gothenburg and the University of Aarhus and at the European Econometric Society Meeting in Dublin, september 1982. Constructive comments from Anders Björklund, Anders Klevmarken, Dale Mortensen, Niels Westergård-Nielsen and several IUI-colleagues are gratefully acknowledged.

I Methodologically, our study is similar to the paper by Rosen and Willis (1979) on education and self-selection and to Lee's analysis (1978) of unionism and wage rates. A recent application of the methodology to analyse migration is provided by Robinson and Tomes (1982). See also Heckman (1979) for a general discussion of self-selection problems in econometric models.

2 This particular form of mobility cost function is suggested by Robinson and Tomes (1982).

3 Mincer (1974).

4 Wu $(1973)$.

5 Jacobsson (1976). 


\section{APPENDIX. ON WAGE LEVEI. AND WAGE CHANGE EQUATIONS}

The point of departure for the analysis of wage growth is the Mincer-type of cross-sectional wage equations, with arguments such as schooling (S), experience (EXP) and possibly other personal characteristics explaining wage levels at each point in time. Assume that the following specifications are valid for the years $t$ and $t-k$,

$$
\begin{aligned}
& \operatorname{lnW}_{i t}=\alpha_{0}+\alpha_{1} S_{i t}+\alpha_{2} \text { EXP }_{i t}+\alpha_{3} \text { EXPSO }_{i t}+\varepsilon_{i t} \text { (A.I) } \\
& \ln _{i t-k}=\beta_{0}+\beta_{1} S_{i t-k}+\beta_{2} \operatorname{EXP}_{i t-k}+\beta_{3} \text { EXPSO }_{i t-k}+\varepsilon_{i t-k}
\end{aligned}
$$

where EXPSO is experience squared. The wage change equation is given by

$$
\begin{aligned}
& \operatorname{InV}_{i}=\alpha_{0}-\beta_{0}+\alpha_{1} \Delta S_{i}+\alpha_{2} \Delta \mathrm{EXP}_{i}+\alpha_{3} \Delta \mathrm{EXPSO}_{i} \\
& \left.+\left(\alpha_{1}-\beta_{1}\right) S_{i t-k}+\left(\alpha_{2}-\beta_{2}\right) \mathrm{EXP}_{i t-k}+\alpha_{3}-\beta_{3}\right) \text { EXPSO }_{i t-k} \\
& +\varepsilon_{i t}-\varepsilon_{i t-k}
\end{aligned}
$$

It is clear from (A.3) that levels of human capital variables belong to a wage change equation only if there are reasons to believe that the coefficients have changed over time. The swedish setting provides an example where the possibility of such effects should be recognized.

Estimation of a wage change equation including the initial levels of all human capital attributes will certainly involve multicollinearity problems. However, a convenient restriction can be imposed by replacing the initial values of the human capital variables with the lagged wage level. This 
restriction implies that all coefficients are forced to change in the same proportion, to the extent that there is some change at all. Assume that the following constraints are imposed on the schooling and experience coefficients,

$$
\begin{aligned}
& \alpha_{1}-\beta_{1}=\delta \beta_{1}, \text { i.e., } \alpha_{1}=\beta_{1}(\delta+1) \\
& \alpha_{2}-\beta_{2}=\delta \beta_{2}, \text { i.e., } \alpha_{2}=\beta_{2}(\delta+1) \\
& \alpha_{3}-\beta_{3}=\delta \beta_{3}, \text { i.e., } \alpha_{3}=\beta_{3}(\delta+1)
\end{aligned}
$$

where $\delta$ is a factor of proportionality, equal to zero if no change of the parameters take place. substituting $(\mathrm{A} .4)-(\mathrm{A} .6)$ into (A.3) yields

$$
\begin{aligned}
& \Delta \operatorname{lnW_{i}}=\alpha_{0}-\beta_{0}+\alpha_{1} \Delta S_{i}+\alpha_{2} \Delta \operatorname{EXP}_{i}+\alpha_{3} \Delta \operatorname{EXPSO}_{i}+ \\
& \delta \beta_{1} S_{i t-k}+\delta \beta_{2} \operatorname{EXP}_{i t-k}+\delta \beta_{3} \operatorname{EXPSQ}_{i t-k}+\varepsilon_{i t}-\varepsilon_{i t-k}
\end{aligned}
$$

From (A.2) we have

$$
\begin{aligned}
& \ln _{i t-k}-\beta_{0}-\varepsilon_{i t-k}= \\
& \beta_{1} S_{i t-k}+\beta_{2} \operatorname{EXP}_{i t-k}+\beta_{3} \operatorname{EXPSO}_{i t-k}
\end{aligned}
$$

Multiplying both sides by $\delta$ and substituting in (A.7) gives

$$
\begin{aligned}
& \Delta \operatorname{lnW_{i}}=\alpha_{0}-\beta_{0}(1+\delta)+\alpha_{1} \Delta S_{i}+\alpha_{2} \Delta \operatorname{EXP} P_{i}+\alpha_{3} \Delta \operatorname{EXPSO} Q_{i} \\
& +\delta \ln W_{i t-k}+\varepsilon_{i t}-(1+\delta) \varepsilon_{i t-k}
\end{aligned}
$$

and hence the proportional shift factor, $\delta$, will show up as the coefficient for the lagged wage 
level. It is clear that $\delta<0$ implies a reduction (in absolute value) of all coefficients.

The presence of a lagged dependent variable introduces some estimation problems, since the composite error term i (A.9) generally will be correlated with the lagged wage rate. However, if the stochastic errors in the wage level equations are autocorrelated,

$\varepsilon_{i t}=\rho \varepsilon_{i t-k}+u_{i t}$

it holds that $\varepsilon_{i t-k}$ drops out if $\rho=1+\delta$. Thus, the consistency of OLS in this context requires that the stochastic errors in the wage level equations follow a particular autocorrelation structure. In the general case oLs will produce inconsistent estimates and an appropriate estimation procedure requires instrumenting the lagged wage rate.

The validity of the specification of the wage change equation in (A.9) is of course conditional on the appropriateness of the specified wage level equations and on the realism of the uniform shifts of the coefficients. A simple check of the latter issue is displayed in Table Al, giving estimated wage level equations for men in the panel we study. A clear pattern is that all coefficients are numerically smaller in 1974, with a mean ratio slightly above 0.5 , implying an average factor of proportionality, $\delta$, somewhat below 0.5 . The pattern of uniform coefficient reductions is rather striking; the restrictions implied by (A.9) thus seem to be roughly supported by the data and will therefore be adhered to in the estimations of wage change equations. 
Table Al Estimated wage level equations for men, 1968 and 1974

\begin{tabular}{|c|c|c|c|c|c|c|}
\hline & \multicolumn{2}{|l|}{1968} & \multicolumn{2}{|l|}{1974} & \multirow{2}{*}{\multicolumn{2}{|c|}{$\begin{array}{l}\text { Ratio between } \\
\text { coefficients } \\
(3) /(1) \quad(4) /(2)\end{array}$}} \\
\hline & (1) & (2) & (3) & (4) & & \\
\hline Constant & $\begin{array}{c}5.846 \\
(151.1)\end{array}$ & $\begin{array}{c}5.766 \\
(140.6)\end{array}$ & $\begin{array}{c}6.822 \\
(168.8)^{2}\end{array}$ & $\begin{array}{c}6.793 \\
(160.4)^{2}\end{array}$ & & \\
\hline Schooling & $\begin{array}{r}0.077 \\
(25.17)\end{array}$ & $\begin{array}{r}0.081 \\
(25.72)\end{array}$ & $\begin{array}{r}0.051 \\
(22.59)\end{array}$ & $\begin{array}{r}0.052 \\
(22.32)\end{array}$ & 0.66 & 0.64 \\
\hline Experience & $\begin{array}{r}0.042 \\
(15.24)\end{array}$ & $\begin{array}{r}0.043 \\
(15.30)\end{array}$ & $\begin{array}{c}0.021 \\
(8.998)\end{array}$ & $\begin{array}{c}0.021 \\
(9.172)\end{array}$ & 0.50 & 0.49 \\
\hline $\begin{array}{l}(\text { Experience })^{2} / \\
1000\end{array}$ & $\begin{array}{r}-0.751 \\
(-12.71)\end{array}$ & $\begin{array}{r}-0.733 \\
(-12.55)\end{array}$ & $\begin{array}{l}-0.323 \\
(-7.862)\end{array}$ & $\begin{array}{c}-0.327 \\
(-7.997)\end{array}$ & 0.43 & 0.45 \\
\hline Marital status & $\begin{array}{c}0.141 \\
(6.482)\end{array}$ & $\begin{array}{c}0.134 \\
(6.156)\end{array}$ & $\begin{array}{c}0.070 \\
(5.030)\end{array}$ & $\begin{array}{c}0.070 \\
(4.004)\end{array}$ & 0.50 & 0.52 \\
\hline $\mathrm{R}^{2}$ & 0.465 & 0.471 & 0.334 & 0.336 & & \\
\hline Sample size & 1231 & 1233 & 1192 & 1192 & & \\
\hline
\end{tabular}

Note: Eqs. (1) and (3) use reported values of experience, whereas (2) and (4) use values of experience calculated as EXP = AGE - S - 7 . Workers with unemployment experiences 1968-74 are not excluded in the samples. 


\section{REFERENCES}

Heckman, J.J., "Sample selection Bias as a Specification Exror". Econometrica, January 1979.

Jacobsson, U., "On the Measurement of the Degree of progression". Journal of Public Economics, January-February. 1976.

Lee, L.F., "Unionism and Wage Rates: A Simultaneous Equations Model with Qualitative and Limited Dependent Variables". International Economic Review, June 1978.

Mincer, J., Schooling, Experience and Earnings. NBER 1974.

Robinson, C., and N. Tomes, "Self-selection and Interprovincial Migration in Canada". Canadian Journal of Economics, August 1982.

Willis, R.J., and S. Rosen, "Education and Self-Selection". Journal of Political Economy, October 1979 .

Wu, D., "Alternative Tests of Independence Between stochastic Regressions and Their Disturbances". Econometrica, July 1973. 
WORKING PAPERS (Missing numbers indicate publication elsewhere)

1976

1. Corporate and Personal Taxation and the Growing Firm by Ulf Jakobsson

7. A Micro Macro Interactive Simulation Model of the Swedish Economy.

Preliminary model specification

by Gunnar Eliasson in collaboration with Gösta Olavi

8. Estimation and Analysis with a WDI Production Function by Göran Eriksson, Ulf Jakobsson and Leif Jansson

1977

12. The Linear Expenditure System and Demand for Housing under Rent Control

by Per Högberg and $\mathrm{N}$ Anders Klevmarken

14. Rates of Depreciation of Human Capital Due to Nonuse by Siv Gustafsson

15. Pay Differentials between Government and Private Sector Employees in Sweden

by Siv Gustafsson

1979

20. A Putty-Clay Model of Demand Uncertainty and Investment by James W. Albrecht and Albert G. Hart

25. On Unexplained Price Differences by Bo Axell

26. The West European Steel Industry - Structure and Competitiveness in Historical Perspective by Bo Carlsson

33. The Demand for Energy in Swedish Manufacturing by Joyce M. Dargay

34. Imperfect Information Equilibrium, Existence, Configuration and Stability by Bo Axell 
1981

35. Value Added Tax: Experience in Sweden by Göran Normann

36. Energi, stabilitet och tillväxt i svensk ekonomi (Energy, Stability and Growth in the Swedish Economy) by Bengt-Christer Ysander

37. Picking Winners or Bailing out Losers? A study of the Swedish state holding company and its role in the new Swedish industrial policy by Gunnar Eliasson and Bengt-Christer Ysander

40. Wage Earners Funds and Rational Expectations by Bo Axell

41. A Vintage Model for the Swedish Iron and Steel Industry by Leif Jansson

43. An Econometric Model of Local Government and Budgeting by Bengt-Christer Ysander

44. Local Authorities, Economic Stability and the Efficiency of Fiscal Policy by Tomas Nordström and Bengt--Christer Ysander

45. Growth, Exit and Entry of Firms by Göran Eriksson

52. Swedish Export Performance 1963-1979. A Constant Market Shares Analysis by Eva Christina Horwitz

56. Central Control of the Local Government Sector in Sweden by Richard Murray

58. Industrial Subsidies in Sweden: Macro-economic Effects and an International Comparison by Bo Carlsson

59. Longitudinal Lessons from the Panel Study of Income Dynamics

by Greg J. Duncan and James N. Morgan 
61. Var står den nationalekonomiska centralteorin idag? av Bo Axell

63. General Search Market Equilibrium by James W. Albrecht and Bo Axell

64. The Structure and Working of the Isac Model by Leif Jansson, Thomas Nordström and Bengt-Christer Ysander

65. Comparative Advantage and Development Policy Twenty Years Later by Anne O. Krueger

67. Computable Multi-Country Models of Production and Trade by James $M$. Henderson

68. Payroll Taxes and Wage Inflation: The Swedish Experiences by Bertil Holmlund (Revised, September 1982).

69. Relative Competitiveness of Foreign Subsidiary Operations of a Multinational Company 1962-77 by Anders Grufman

70. Optimization under nonlinear constraints by Leif Jansson and Erik Mellander

71. Technology, Pricing and Investment in Telecommunications by Tomas Pousette

72. The Micro Initialization of MOSES by James W Albrecht and Thomas Lindberg

73. Measuring the Duration of Unemployment: A Note by Anders Björklund

74. On the Optimal Rate of Structural Adjustment by Gunnar Eliasson

75. The MOSES Manual by Fredrik Bergholm

76. Differential patterns of Unemployment in Sweden by Linda Leighton and Siv Gustafsson 
77. Household Market and a Nonmarket Activities (HUS)

- A Pilot Study

by Anders Klevmarken

78. Arbetslöshetsersättningen i Sverige

- motiv, regler och effekter

av Anders Björklund och Bertil Holmlund

1983

79. Energy Prices, Industrial Structure and Choice of

Technology; An International Comparison with Special

Emphasis on the Cement Industry

by Bo Carlsson

80. Energy Usage and Energy Prices in Swedish Manufacturing by Joyce Dargay

81. ELIAS - A Model of Multisectoral Economic Growth in a Small Open Economy

by Lars Bergman

82. Oil Prices and Economic Stability - Simulation

Experiments with a Macroeconomic Model

by Tomas Nordström and Bengt--Christer Ysander

83. Statlig kontroll av kommunerna

En översikt av svenska erfarenheter under efterkrigstiden

av Richard Murray och Bengt-Christer Ysander

84. Monopoly and Allocative Efficiency with Stochastic Demand by Tomas Pousette

85. Export Performance of the Nordic Countries 1965-80

A Constant-Market-Shares Analysis

by Eva Christina Horwitz.

86. The Micro (Firm) Foundations of Industrial Policy by Gunnar Eliasson

87. Excessive Government Spending in the U.S.: Facts and Theories

by Edward M. Gramlich.

88. Control of Local Authority Expenditure - The Use of Cash Limits

by Noel Hepworth

89. Fiscal Containment and Local Government Finance in The U.K.

by Peter Jackson 
90. Fiscal Limitations: An Assessment of the U.S. Experience

by Wallace E. Oates

91. Pricing and Privatization of Public Services by George E. Peterson

92. Export Performance of the Nordic Countries 1965-80

by Eva Christina Horwitz

93. Was Adam Smith Right, After All?

Another Test of the Theory of Compensating Wage Differentials

by Greg J. Duncan and Bertil Holmlund

94. Job Mobility and Wage Growth:

A Study of Selection Rules and Rewards

by Bertil Holmlund 